Annals of Pure and Applied Mathematics

Vol. 14, No. 1, 2017, 11-19

ISSN: 2279-087X (P), 2279-0888(online)

Published on 1 June 2017

www.researchmathsci.org

DOI: http://dx.doi.org/10.22457/apam.v14n1a2

Annals of

Pure and Applied

Mathematics

\title{
New Results on Labelings of Central Graph of Barbell Graph
}

\author{
P. Agasthi ${ }^{1}$, N. Parvathi ${ }^{2}$ and K. Thirusangu ${ }^{3}$ \\ ${ }^{1}$ Department of Mathematics, Tagore Engineering College \\ Rathinamangalam, Vandalur, Chennai - 600048 \\ Corresponding author. Email: agasthipadmanathan@yahoo.com \\ ${ }^{2}$ Department of Mathematics, SRM University \\ Kattankulathur - 603203 \\ ${ }^{3}$ Department of Mathematics, S.I.V.E.T College \\ Gowrivakkam, Chennai - 600 073. E-mail: kthirusangu@gmail.com
}

Received 10 May 2017; accepted 27 May 2017

\begin{abstract}
A Barbell graph $\mathrm{B}(\mathrm{p}, \mathrm{n})$ is the graph obtained by connecting $\mathrm{n}$-copies of a complete graph $\mathrm{K}_{\mathrm{p}}$ by a bridge. A central graph of Barbell graph $\mathrm{C}(\mathrm{B}(\mathrm{p}, \mathrm{n}))$ is the graph obtained by subdividing each edge of $\mathrm{B}(\mathrm{p}, \mathrm{n})$ exactly once and joining all the non adjacent vertices of $B(p, n)$. In this paper, the ways to construct root mean square, square sum, square difference, cordial, total cordial labelings of central graph of Barbell graphs are reported.
\end{abstract}

Keywords: Barbell graph, central graph of barbell graph, root mean square labeling, square sum labeling, square difference labeling, cordial labeling, total cordial labeling.

\section{AMS Mathematics Subject Classification (2010): 05 C78}

\section{Introduction}

The graphs considered here are finite, undirected and simple. The concept of graph labeling was introduced by Rosa in 1967. Let G (V, E) be a (p, q) graph. The mean labeling was introduced by Somasundram and Ponraj [2]. Root square mean labeling was introduced by Sandhya, Somasundram and Anusa in [3]. The square sum and square difference labelings were introduced by Ajitha, Arumugam and Germina [4]. They proved that $\mathrm{K}_{\mathrm{p}}(\mathrm{p} \leq 5)$ have square-sum and square difference labelings. The concept of cordial, and total cordial labelings was introduced by Sundaram and Somasundaram [5]. The existence of cordial labeling of trees, helms, triangular snakes, cycles total graph of $P_{n}$ and some of their related graph like $P_{m} \cup P_{n}, P_{m} \times P_{n}, C_{m} \cup P_{n}$ etc., have been studied in the literature. In this paper we prove that the existence of root square mean, square sum, square difference, cordial and total cordial labelings of Central graph of Barbell graph $\mathrm{C}(\mathrm{B}(\mathrm{p}, \mathrm{n}))$ for all $\mathrm{p} \geq 3$ and $\mathrm{n}=2$.

Definition 1.1. Let $G$ be a $(p, q)$ graph. A graph $G$ admits root mean square labeling if there exist a injective mapping from the vertices of $G$ to set $\{0,1,2,3, \ldots, 2 p\}$ such that 
when each edge $u v$ is assigned the label $f(u v)=\sqrt{\frac{[f(u)]^{2}+[f(v)]^{2}}{2}}$, then the resulting edge labels are distinct numbers.

Definition 1.2. Let $\mathrm{G}$ be a $(\mathrm{p}, \mathrm{q})$ graph. A one-one map $\mathrm{f}: \mathrm{V}(\mathrm{G}) \rightarrow\{0, \ldots, \mathrm{p}-1\}$ is said to be a square sum labeling if the induced map $\mathrm{f}^{*}(\mathrm{uv})=(\mathrm{f}(\mathrm{u}))^{2}+(\mathrm{f}(\mathrm{v}))^{2}$ is injective. It is said to be a square difference labeling if the induced map $\mathrm{f}^{*}(\mathrm{uv})=(\mathrm{f}(\mathrm{u}))^{2}-(\mathrm{f}(\mathrm{v}))^{2}$ is injective.

Definition 1.3. A mapping $\mathrm{f}: \mathrm{V}(\mathrm{G}) \rightarrow\{0,1\}$ is called binary vertex labeling of $\mathrm{G}$ and $f(v)$ is called the label of the vertex $v$ of $G$ under $f$.

The induced edge labeling $\mathrm{f}^{*}: \mathrm{E}(\mathrm{G}) \rightarrow\{0,1\}$ is given by $\mathrm{f}^{*}(\mathrm{e}=\mathrm{uv})=|\mathrm{f}(\mathrm{u})-\mathrm{f}(\mathrm{v})|$.

Definition 1.4. A binary vertex labeling of a graph $G$ is called a cordial labeling if $\mid v_{f}(0)-$ $\mathrm{v}_{\mathrm{f}}(1) \mid \leq 1$ and $\left|\mathrm{e}_{\mathrm{f}}(0)-\mathrm{e}_{\mathrm{f}}(1)\right| \leq 1$, where

$\mathrm{v}_{\mathrm{f}}(0)=$ number of vertices of $\mathrm{G}$ having label 0 under $\mathrm{f}$.

$v_{\mathrm{f}}(1)=$ number of vertices of $G$ having label 1 under $f$.

$\mathrm{e}_{\mathrm{f}}(0)=$ number of edges of $\mathrm{G}$ having label 0 under $\mathrm{f}^{*}$.

$\mathrm{e}_{\mathrm{f}}(1)=$ number of edges of $\mathrm{G}$ having label 1 under $\mathrm{f}^{*}$.

A graph $\mathrm{G}$ is called cordial if it admits cordial labeling.

Definition 1.5. A total-cordial labeling of a graph $\mathrm{G}$ with vertex set $\mathrm{V}$ and edge set $\mathrm{E}$ as an cordial labeling if $\left|\left(\mathrm{v}_{\mathrm{f}}(0)+\mathrm{e}_{\mathrm{f}}(0)\right)-\left(\mathrm{v}_{\mathrm{f}}(1)+\mathrm{e}_{\mathrm{f}}(1)\right)\right| \leq 1$.

Definition 1.6. The central graph of $\mathrm{G}$, denoted by $\mathrm{C}(\mathrm{G})$ is obtained by subdividing each edge of $\mathrm{G}$ exactly once and joining all the non-adjacent vertices of $\mathrm{G}$. Consider the Barbell graph $\mathrm{B}(\mathrm{p}, \mathrm{n})$ formed by $\mathrm{n}$-copies of the complete graph $K_{p}$ with vertices $v_{i}$, $1 \leq i \leq n p$ named in counter clockwise direction. By the definition of $\mathrm{C}(\mathrm{B}(\mathrm{p}, \mathrm{n}))$, each edge of $\mathrm{B}(\mathrm{p}, \mathrm{n})$ is subdivided by the vertex $c_{j}, n p+1 \leq j \leq p^{2}+(p+1)$.

\section{Structural properties of $C(B(p, n))$}

Throughout this paper we denote the Barbell graph as $\mathrm{B}(\mathrm{p}, \mathrm{n})$. The number of vertices in the central graph of $\mathrm{B}(\mathrm{p}, \mathrm{n}), \mathrm{C}(\mathrm{B}(\mathrm{p}, \mathrm{n}))$ is $\frac{n\left(p^{2}+p\right)+\mathrm{n}}{2}$ and the number of edges in $\mathrm{C}(\mathrm{B}(\mathrm{p}, \mathrm{n}))$ is $\left(3 p^{2}-2 p+1\right)$. Clearly, exactly $2 \mathrm{p}$ vertices is of degree $(2 p-1)$ and the rest of the vertices are of degree 2 .

\section{Main results}

Theorem 2.1. The central graph of Barbell graph $C(B(p, n))$ is a root mean square graph for all $\mathrm{p} \geq 3$ and $\mathrm{n}=2$.

Proof: Let $\mathrm{G}=\mathrm{C}(\mathrm{B}(\mathrm{p}, \mathrm{n}))$

The vertex set of $\mathrm{G}$ is $\mathrm{W}=V_{i} \cup C_{j}$

Define $\mathrm{f}: \mathrm{W}(\mathrm{G}) \rightarrow\left\{0,1,2, \ldots, \frac{n\left(p^{2}+P\right)+\mathrm{n}}{2}\right\}$ as follows

$$
\mathrm{f}\left(\mathrm{v}_{\mathrm{i}}\right)=\mathrm{i}-1,1 \leq \mathrm{i} \leq \mathrm{np} .
$$


New Results on Labelings of Central Graph of Barbell Graph

$$
f\left(c_{j}\right)=j-1, n p+1 \leq j \leq p^{2}+(p+1)
$$

Thus the labels of the vertices are given below:

$$
\begin{aligned}
& \mathrm{f}\left(\mathrm{V}_{\mathrm{i}}\right)=\{0,1,2,3,4, \ldots,((\mathrm{np})-1)\} \\
& \mathrm{f}\left(\mathrm{C}_{\mathrm{j}}\right)=\left\{\mathrm{np},(\mathrm{np}+1), \ldots,\left(\mathrm{p}^{2}+(\mathrm{p}+1)\right)-1\right\}
\end{aligned}
$$

Define the induced function on edges as $\mathrm{f}^{*}: \mathrm{E} \rightarrow \mathrm{N}$ such that

$$
\begin{aligned}
& \mathrm{f}^{*}\left(\mathrm{v}_{\mathrm{i}} \mathrm{c}_{\mathrm{j}}\right)=\sqrt{\frac{f\left(v_{i}\right)^{2}+f\left(\mathrm{c}_{j}\right)^{2}}{2}} \\
& \therefore \mathrm{f}^{*}\left(\mathrm{v}_{\mathrm{i}} \mathrm{c}_{\mathrm{j}}\right)=\sqrt{\frac{(\mathrm{i}-1)^{2}+(j-1)^{2}}{2}}
\end{aligned}
$$

To prove $\mathrm{f}^{*}$ is injective we have to prove

$$
\mathrm{f}^{*}\left(\mathrm{v}_{\mathrm{i}} \mathrm{c}_{\mathrm{j}}\right) \neq \mathrm{f}^{*}\left(\mathrm{v}_{\mathrm{i}+1} \mathrm{c}_{\mathrm{j}+1}\right) \text {, when } \mathrm{i} \neq \mathrm{j}
$$

Now $\mathrm{f}^{*}\left(\mathrm{v}_{\mathrm{i}+1} \mathrm{c}_{\mathrm{j}+1}\right)=\sqrt{\frac{i^{2}+j^{2}}{2}}$.

Since $\sqrt{\frac{(\mathrm{i}-1)^{2}+(j-1)^{2}}{2}} \neq \sqrt{\frac{i^{2}+j^{2}}{2}}$, when $\mathrm{i} \neq \mathrm{j}$, we have $\mathrm{f}^{*}\left(\mathrm{v}_{\mathrm{i}} \mathrm{c}_{\mathrm{j}}\right) \neq \mathrm{f}^{*}\left(\mathrm{v}_{\mathrm{i}+1} \mathrm{c}_{\mathrm{j}+1}\right)$

Therefore, all edge labels are distinct.

Hence $\mathrm{C}(\mathrm{B}(\mathrm{p}, \mathrm{n}))$ admits root mean square labeling.

Example 1.1. Root mean square labeling of $\mathrm{C}(\mathrm{B}(3,2))$ and $\mathrm{C}(\mathrm{B}(4,2))$ are given in the following figure 1.

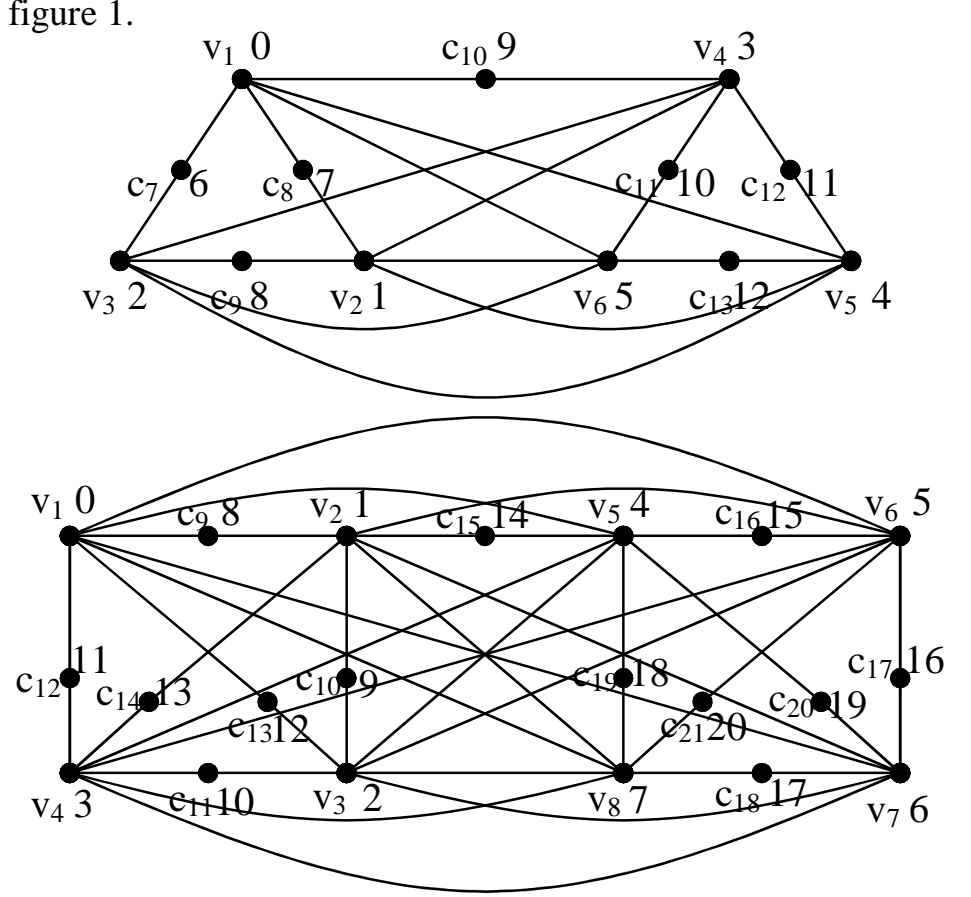

Figure1: The root mean square labeling of $\mathrm{C}(\mathrm{B}(3,2)), \mathrm{C}(\mathrm{B}(4,2))$ 
P. Agasthi, N. Parvathi and K. Thirusangu

Theorem 2.2. The central graph of Barbell graph $\mathrm{C}(\mathrm{B}(\mathrm{p}, \mathrm{n}))$ is a square sum graph for all $\mathrm{p} \geq 3$ and $\mathrm{n}=2$.

Proof: Let $\mathrm{G}=\mathrm{C}(\mathrm{B}(\mathrm{p}, \mathrm{n}))$. The vertex set of $\mathrm{G}$ is $\mathrm{W}=V_{i} \cup C_{j}$

Define $\mathrm{f}: \mathrm{W}(\mathrm{G}) \rightarrow\left\{0,1,2, \ldots, \frac{n\left(p^{2}+P\right)+\mathrm{n}}{2}\right\}$ as follows

$$
\begin{aligned}
& \mathrm{f}\left(\mathrm{v}_{\mathrm{i}}\right)=\mathrm{i}-1,1 \leq \mathrm{i} \leq \mathrm{np} . \\
& \mathrm{f}\left(\mathrm{c}_{\mathrm{j}}\right)=\mathrm{j}-1, \mathrm{np}+1 \leq \mathrm{j} \leq \mathrm{p}^{2}+(\mathrm{p}+1)
\end{aligned}
$$

Thus the labels of the vertices are given below:

$$
\begin{aligned}
& \mathrm{f}\left(\mathrm{V}_{\mathrm{i}}\right)=\{0,1,2,3,4, \ldots,((\mathrm{np})-1)\} \\
& \mathrm{f}\left(\mathrm{C}_{\mathrm{j}}\right)=\left\{\mathrm{np},(\mathrm{np}+1), \ldots,\left(\mathrm{p}^{2}+(\mathrm{p}+1)\right)-1\right\}
\end{aligned}
$$

Define the induced function on edges as $\mathrm{f}^{*}: \mathrm{E} \rightarrow \mathrm{N}$ such that

$$
\begin{aligned}
& \mathrm{f}^{*}\left(\mathrm{v}_{\mathrm{i}} \mathrm{c}_{\mathrm{j}}\right)=\mathrm{f}\left(\mathrm{v}_{\mathrm{i}}\right)^{2}+\mathrm{f}\left(\mathrm{c}_{\mathrm{j}}\right)^{2} \\
& \therefore \mathrm{f}^{*}\left(\mathrm{v}_{\mathrm{i}} \mathrm{c}_{\mathrm{j}}\right)=(\mathrm{i}-1)^{2}+(\mathrm{j}-1)^{2}
\end{aligned}
$$

To prove $\mathrm{f}^{*}$ is injective we have to prove

$$
\mathrm{f}^{*}\left(\mathrm{v}_{\mathrm{i}} \mathrm{c}_{\mathrm{j}}\right) \neq \mathrm{f}^{*}\left(\mathrm{v}_{\mathrm{i}+1} \mathrm{c}_{\mathrm{j}+1}\right) \text {, when } \mathrm{i} \neq \mathrm{j}
$$

Now $f^{*}\left(v_{i+1} c_{j+1}\right)=i^{2}+j^{2}$

Since $(i-1)^{2}+(j-1)^{2} \neq i^{2}+j$, when $i \neq j$, we have $f^{*}\left(v_{i} c_{j}\right) \neq f^{*}\left(v_{i+1} c_{j+1}\right)$

Therefore, all edge labels are distinct. Hence $\mathrm{C}(\mathrm{B}(\mathrm{p}, \mathrm{n}))$ admits square sum labeling.

xample 1.2. Square sum labeling of $\mathrm{C}(\mathrm{B}(3,2))$ and $\mathrm{C}(\mathrm{B}(4,2))$ are given in the following figure 2 .
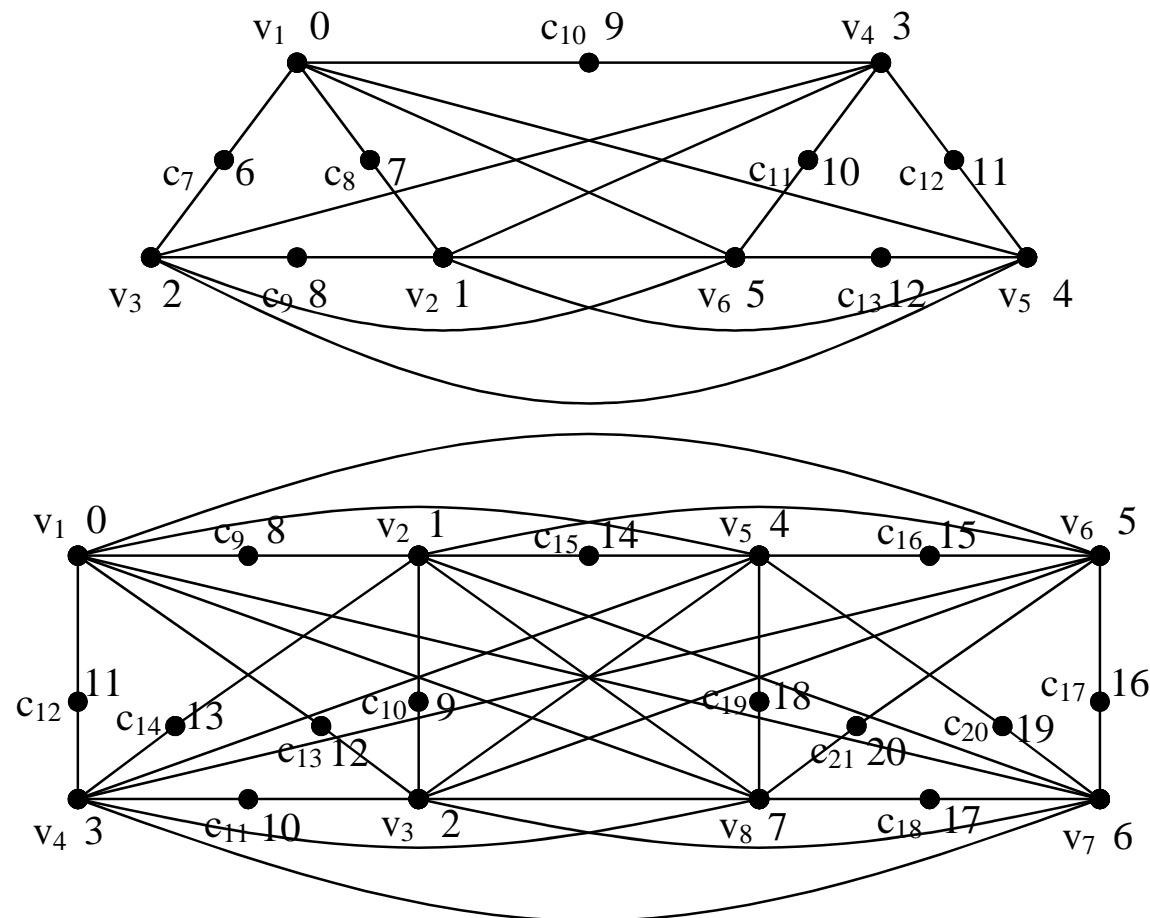

Figure 2: The square-sum labeling of $\mathrm{C}(\mathrm{B}(3,2)), \mathrm{C}(\mathrm{B}(4,2))$ 
New Results on Labelings of Central Graph of Barbell Graph

Theorem 2.3. The central graph of Barbell graph $\mathrm{C}(\mathrm{B}(\mathrm{p}, \mathrm{n}))$ is a square difference graph for all $\mathrm{p} \geq 3$ and $\mathrm{n}=2$.

Proof: Let $\mathrm{G}=\mathrm{C}(\mathrm{B}(\mathrm{p}, \mathrm{n}))$. The vertex set of $\mathrm{G}$ is $\mathrm{W}=V_{i} \cup C_{j}$.

Define $\mathrm{f}: \mathrm{W}(\mathrm{G}) \rightarrow\left\{0,1,2, \ldots, \frac{n\left(p^{2}+P\right)+\mathrm{n}}{2}\right\}$ as follows

$$
\begin{aligned}
& \mathrm{f}\left(\mathrm{v}_{\mathrm{i}}\right)=\mathrm{i}-1,1 \leq \mathrm{i} \leq \mathrm{np} . \\
& \mathrm{f}\left(\mathrm{c}_{\mathrm{j}}\right)=\mathrm{j}-1, \mathrm{np}+1 \leq \mathrm{j} \leq \mathrm{p}^{2}+(\mathrm{p}+1)
\end{aligned}
$$

Thus the vertex labeled sets are given below:

$$
\begin{aligned}
& \mathrm{f}\left(\mathrm{V}_{\mathrm{i}}\right)=\{0,1,2,3,4, \ldots,((\mathrm{np})-1)\} \\
& \mathrm{f}\left(\mathrm{C}_{\mathrm{j}}\right)=\left\{\mathrm{np},(\mathrm{np}+1), \ldots,\left(\mathrm{p}^{2}+(\mathrm{p}+1)\right)-1\right\}
\end{aligned}
$$

Define the induced function on edges as $\mathrm{f}^{*}: \mathrm{E} \rightarrow \mathrm{N}$ such that

$$
\begin{aligned}
& \mathrm{f}^{*}\left(\mathrm{v}_{\mathrm{i}} \mathrm{c}_{\mathrm{j}}\right)=\mathrm{f}\left(\mathrm{v}_{\mathrm{i}}\right)^{2}-\mathrm{f}\left(\mathrm{c}_{\mathrm{j}}\right)^{2} \\
& \therefore \mathrm{f}^{*}\left(\mathrm{v}_{\mathrm{i}} \mathrm{c}_{\mathrm{j}}\right)=(\mathrm{i}-1)^{2}-(\mathrm{j}-1)^{2}
\end{aligned}
$$

To prove $f^{*}$ is injective we have to prove $f^{*}\left(v_{i} c_{j}\right) \neq f^{*}\left(v_{i+1} c_{j+1}\right)$, when $i \neq j$.

Now $f^{*}\left(v_{i+1} c_{j+1}\right)=i^{2}-j^{2}$

Since $(i-1)^{2}-(j-1)^{2} \neq i^{2}-j^{2}$, when $i \neq j$, we have $f^{*}\left(v_{i} c_{j}\right) \neq f^{*}\left(v_{i+1} c_{j+1}\right)$

Therefore, all edge labels are distinct.

Hence $\mathrm{C}(\mathrm{B}(\mathrm{p}, \mathrm{n}))$ admits square difference labeling.

Example 1.3. Square difference labeling of $\mathrm{C}(\mathrm{B}(3,2)$ and $\mathrm{C}(\mathrm{B}(4,2))$ are shown in following figure 3 .

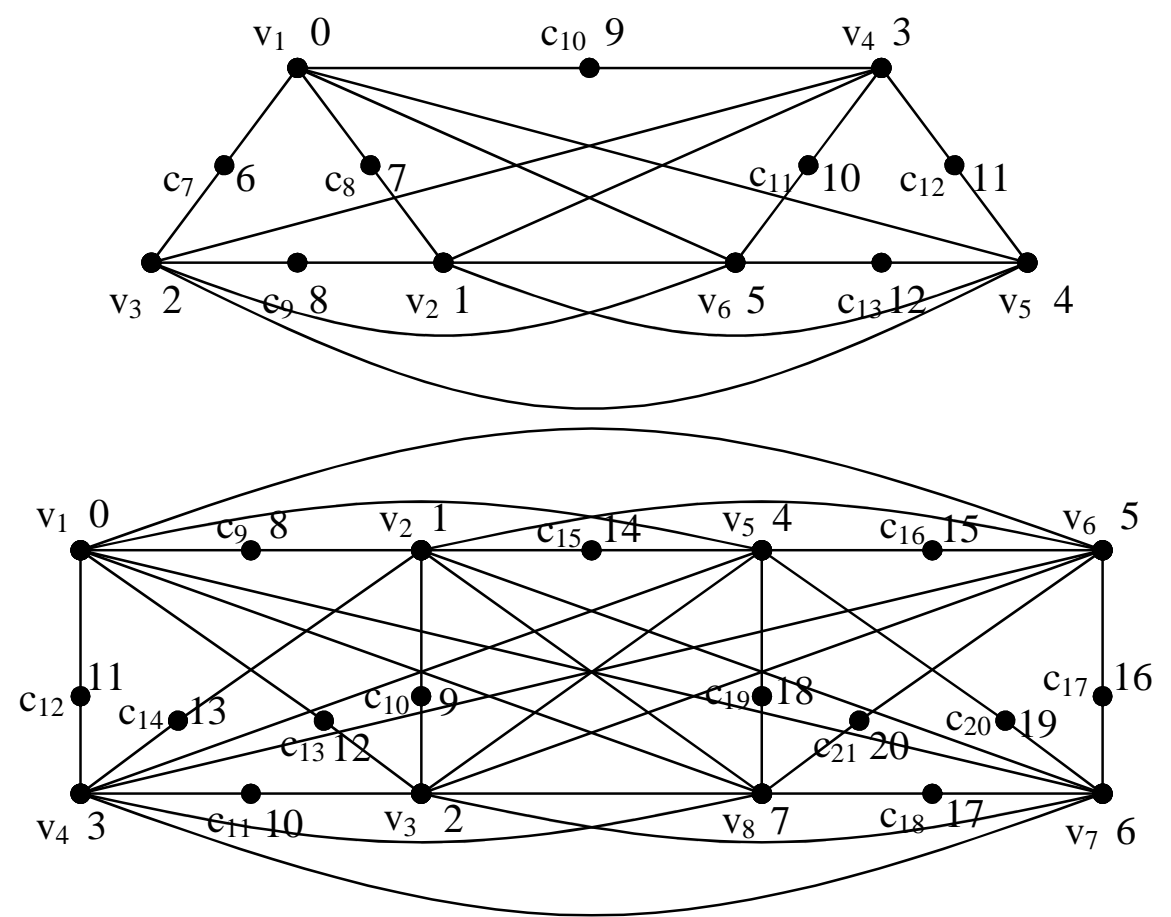

Figure 3: The square difference labeling of $\mathrm{C}(\mathrm{B}(3,2)), \mathrm{C}(\mathrm{B}(4,2))$ 
P. Agasthi, N. Parvathi and K. Thirusangu

Theorem 2.4. The central graph of Barbell graph $C(B(p, n))$ is a cordial graph for all $p \geq$ 3 and $n=2$.

Proof: Let $\mathrm{G}=\mathrm{C}(\mathrm{B}(\mathrm{p}, \mathrm{n}))$.

The vertex set of $\mathrm{G}$ is $\mathrm{W}=V_{i} \cup C_{j}$.

Define $\mathrm{f}: \mathrm{W}(\mathrm{G}) \rightarrow\{0,1\}$ as follows

$$
\begin{aligned}
& f\left(v_{i}\right)=\left\{\begin{array}{l}
0, \text { for } i \equiv 1(\bmod 2) \\
1, \text { for } i \equiv 0(\bmod 2), 1 \leq i \leq n p
\end{array}\right\} \\
& f\left(c_{j}\right)=\left\{\begin{array}{l}
0, \text { for } \equiv 1(\bmod 2) \\
1, \text { for } \equiv 0(\bmod 2), n p+1 \leq j \leq p^{2}+(p+1)
\end{array}\right\}
\end{aligned}
$$

Define the induced function on edges as $\mathrm{f} *: \mathrm{E} \rightarrow \mathrm{N}$ such that

$f^{*}\left(v_{i} c_{j}\right)=\left|f\left(v_{i}\right)-f\left(c_{j}\right)\right|$

The vertex $c_{j}$ has been abstracted from $v_{i} v_{i+1}$. As a result the two edges $v_{i} c_{j}, c_{j} v_{i+1}$ has arrived.

When $i \equiv 1(\bmod 2), j \equiv 1(\bmod 2)$

$$
\begin{aligned}
f^{*}\left(v_{i} c_{j}\right) & =\left|f\left(v_{i}\right)-f\left(c_{j}\right)\right| \\
& =0
\end{aligned}
$$

When $i \equiv 1(\bmod 2), j \equiv 0(\bmod 2)$

$$
f^{*}\left(v_{i} c_{j}\right)=\left|f\left(v_{i}\right)-f\left(c_{j}\right)\right|=1
$$

When $i \equiv 0(\bmod 2), j \equiv 1(\bmod 2)$

$$
f^{*}\left(v_{i} c_{j}\right)=\left|f\left(v_{i}\right)-f\left(c_{j}\right)\right|=1
$$

When $i \equiv 0(\bmod 2), j \equiv 0(\bmod 2)$

$$
f^{*}\left(v_{i} c_{j}\right)=\left|f\left(v_{i}\right)-f\left(c_{j}\right)\right|=0
$$

Thus in each cases we have

$$
\left|\mathrm{v}_{\mathrm{f}}(0)-\mathrm{v}_{\mathrm{f}}(1)\right| \leq 1 \text { and }\left|\mathrm{e}_{\mathrm{f}}(0)-\mathrm{e}_{\mathrm{f}}(0)\right| \leq 1 \text {. }
$$

Hence $\mathrm{C}(\mathrm{B}(\mathrm{p}, \mathrm{n}))$ is cordial.

Example 1.4. Cordial labeling of $\mathrm{C}(\mathrm{B}(3,2))$ and $\mathrm{C}(\mathrm{B}(4,2))$ are given in following figure 4.

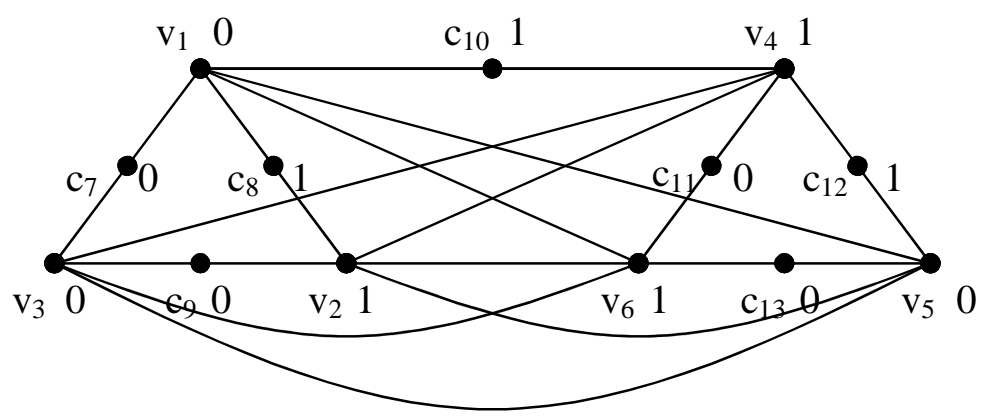


New Results on Labelings of Central Graph of Barbell Graph

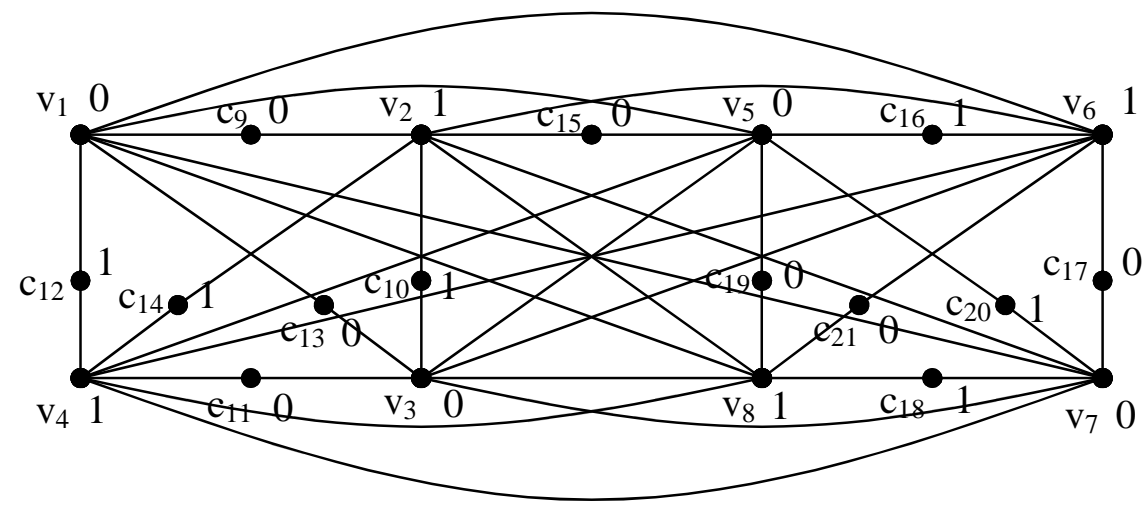

Figure 4: The cordial labeling of $\mathrm{C}(\mathrm{B}(3,2)), \mathrm{C}(\mathrm{B}(4,2))$

Theorem 2.5. The central graph of Barbell graph $\mathrm{C}(\mathrm{B}(\mathrm{p}, \mathrm{n}))$ is a total cordial graph for all $\mathrm{p} \geq 3$ and $\mathrm{n}=2$.

Proof: Let $\mathrm{G}=\mathrm{C}(\mathrm{B}(\mathrm{p}, \mathrm{n}))$.

The vertex set of $\mathrm{G}$ is $\mathrm{W}=V_{i} \cup C_{j}$.

Define $\mathrm{f}: \mathrm{W}(\mathrm{G}) \rightarrow\{0,1\}$ as follows

$$
\begin{aligned}
& f\left(v_{i}\right)=\left\{\begin{array}{l}
0, \text { for } i \equiv 1(\bmod 2) \\
1, \text { for } i \equiv 0(\bmod 2), 1 \leq i \leq n p
\end{array}\right\} \\
& f\left(c_{j}\right)=\left\{\begin{array}{l}
0, \text { for } \equiv 1(\bmod 2) \\
1, \text { forj } \equiv 0(\bmod 2), n p+1 \leq j \leq p^{2}+(p+1)
\end{array}\right\}
\end{aligned}
$$

Define the induced function on edges as $\mathrm{f} *: \mathrm{E} \rightarrow \mathrm{N}$ such that $f^{*}\left(v_{i} c_{j}\right)=\left|f\left(v_{i}\right)-f\left(c_{j}\right)\right|$.

The vertex $c_{j}$ has been abstracted from $v_{i} v_{i+1}$. As a result the two edges $v_{i} c_{j}, c_{j} v_{i+1}$ has arrived.

When $i \equiv 1(\bmod 2), j \equiv 1(\bmod 2)$

$$
\begin{aligned}
f^{*}\left(v_{i} c_{j}\right) & =\left|f\left(v_{i}\right)-f\left(c_{j}\right)\right| \\
& =0
\end{aligned}
$$

When $i \equiv 1(\bmod 2), j \equiv 0(\bmod 2)$

$$
\begin{aligned}
f^{*}\left(v_{i} c_{j}\right) & =\left|f\left(v_{i}\right)-f\left(c_{j}\right)\right| \\
& =1
\end{aligned}
$$

When $i \equiv 0(\bmod 2), j \equiv 1(\bmod 2)$

$$
\begin{aligned}
f^{*}\left(v_{i} c_{j}\right) & =\left|f\left(v_{i}\right)-f\left(c_{j}\right)\right| \\
& =1
\end{aligned}
$$

When $i \equiv 0(\bmod 2), j \equiv 0(\bmod 2)$

$$
f^{*}\left(v_{i} c_{j}\right)=\left|f\left(v_{i}\right)-f\left(c_{j}\right)\right|=0 \text {. }
$$


P. Agasthi, N. Parvathi and K. Thirusangu

Thus in each cases we have $\left|\left(\mathrm{v}_{\mathrm{f}}(0)+\mathrm{e}_{\mathrm{f}}(0)\right)-\left(\mathrm{v}_{\mathrm{f}}(1)+\mathrm{e}_{\mathrm{f}}(1)\right)\right| \leq 1$.

Hence $\mathrm{C}(\mathrm{B}(\mathrm{p}, \mathrm{n}))$ is total cordial.

Example 1.5 Total cordial labeling of $\mathrm{C}(\mathrm{B}(3,2))$ and $\mathrm{C}(\mathrm{B}(4,2))$ are given in the following figure 5 .
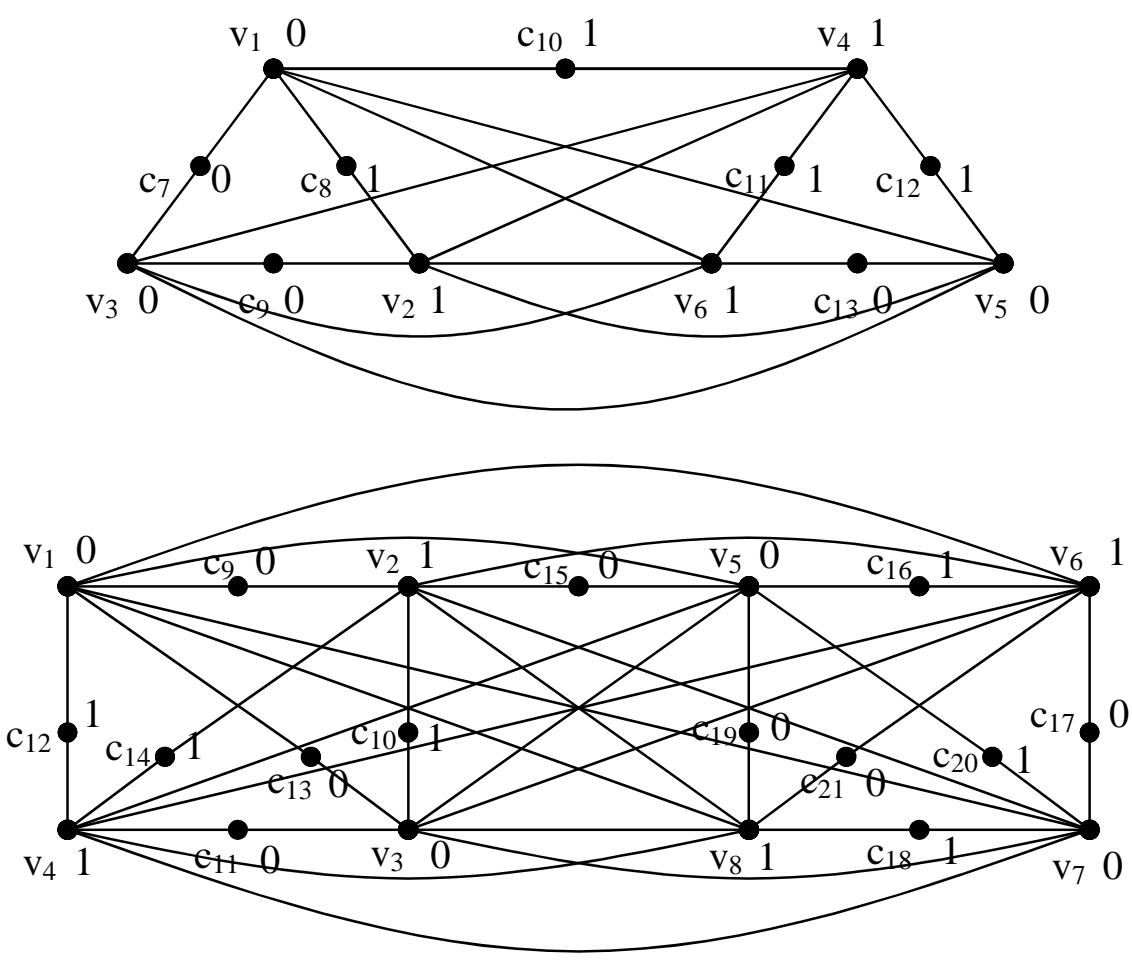

Figure 5: The total cordial labeling of $\mathrm{C}(\mathrm{B}(3,2))$ and $\mathrm{C}(\mathrm{B}(4,2))$

\section{Conclusion}

In this paper, we have examined the existence of root mean square, square sum, square difference, cordial, total cordial labelings for central graph of barbell graph for all $\mathrm{P} \geq 3$ and $n=2$. Further investigation can be done to obtain the above labeling for some class of graphs.

\section{REFERENCES}

1. J.A.Gallian, A dynamic survey of graph labeling, The Electonic Journal of Combinatorics, 17 (2014).

2. S.Somasundaram and R.Ponraj, Mean labeling of graphs, National Academy Science Letters, 26 (2003) 210-213.

3. S.S.Sandhya, S.Somasundaram and S.Anusa, Root square mean labeling of Graphs, Int. J. Contemp. Math. Sciences, 9(14) (2014) 667-676. 
New Results on Labelings of Central Graph of Barbell Graph

4. V.Ajtha, S.Arumugam and K.A.Germina, On square sum graphs, AKCE J. Graphs, Combin., 6 (2009) 1-10.

5. M.Sundaram, R.Ponraj and S.Somasundaram, Some results on total product cordial labeling of graphs, J. Indian Acad. Math., 28 (2006) 309-320.

6. P.Agasthi, N.Parvathi and K.Thirusangu, On some labelings of Barbell Graph, Global Journal of Pure and Applied Mathematics, 12(1) (2016) 273-280.

7. K.Thirusangu, P.P.Ulaganathan and P.Vijaya Kumar, Some cordial labeling of duplicate graph of ladder graph, Annals of Pure and Applied Mathematics, 8(2) (2014) 43-50.

8. K.Sutha, K.Thirusangu and S.Bala, Some graph labeling on middle graph of extended duplicate graph of a path, Annals of Pure and Applied Mathematics, 8(2) (2014) 169-174.

9. V.Celin Mary, K.Thirusangu and S.Bala, Labelings On Jahangir graph and extended duplicate graph of Jahangir graph, Annals of Pure and Applied Mathematics, 8(2) (2014) 143-151. 